\title{
Ten Rules of Academic Writing ${ }^{1}$
}

\section{STEPHEN K. DONOVAN}

Creative writers are well served with 'how to' guides, but just how much do they help? And how might they be relevant to academic authors? A recent survey of writing tips by twenty-eight creative authors has been condensed to the ten most relevant to the academic, supported by some comments on methodology and applicability.

Keywords: academic writing, methodology, how to, editing

Simple formulae exist for solving some problems, but not for others. When I was a telephone engineer in London during the mid-1970s, the mechanical complexity of an exchange working on the Strowger electromechanical system was distilled into a series of truly comprehensive tomes called TIs, or Telecommunications Instructions. They explained the significance and structure of every last piece of switching equipment and cabling, how it worked, and how to fix it. Exchange faults outside the limits of the TIs existed, rarely, but were regarded by some rather as a wild creature to be hunted down and eradicated than as a technical problem.

Contrast this comprehensive source of information with so many other aspects of life, particularly in the non-mechanical world. Is there a right way to make a cup of tea? Some aspects might be regarded as essential — using boiling water - whereas many are subject to debate warm the pot in advance or not (or is a pot even necessary?). Writing is, of course, more akin to making a pot of tea than to maintaining a telephone exchange. There is an extensive literature on how to write anything and everything, including CVs, speeches, poems, biographies, family histories, novels, academic research papers, and monographs. I do not know to what extent these self-help books are of assistance, although it must be assumed that they help at least some nascent writers, but I do know that I enjoy reading them to see how they contradict each other. As one illustrative example among many, humour in public 
presentations is viewed positively by some authors ${ }^{2}$ and considered less desirable by others. ${ }^{3}$ If you read widely enough, there is an excellent chance that you will find a book or books to support (or contradict) any and all of your preconceptions and prejudices. So how do they help?

Flying into the United Kingdom recently, I was intrigued by a long article in the Saturday 'Review' section of a newspaper giving tips for aspiring writers from established authors. ${ }^{4}$ This had been inspired by the then forthcoming, now published, book 10 Rules of Writing. ${ }^{5}$ In response to a request to contribute, replies (up to ten per author) varied from the focused ('Writing is work' - Margaret Atwood) and planned ('Keep a diary' - Geoff Dyer) to the personal ('The writing life is essentially one of solitary confinement' - Will Self), the terse ('Be consistent' - Ian Rankin), and the dismissive ('My main rule is to say no to things like this' - Philip Pullman).

All worthwhile comments and solid advice for the creative writerbut do they apply to academic scribblers like ourselves? Unexpectedly, I found much of what was said also applicable to my style of academic writing. This is probably because the newspaper article was concerned more with the nuts and bolts of creative writing sensu lato than with, for example, plotting your novel. Further, and not surprisingly, many of the most basic recommendations are repeated by different authors. I have tried to extract from this article the essence of these basic recommendations and suggestions, and distil them down to ten rules of academic writing. For each of the following I include the name of the contributor who made the suggestion, but most were repeated by more than one of the twenty-eight participating authors.

\section{ALWAYS CARRY A NOTEBOOK (WILL SELF)}

An essential adjunct to thinking, a notebook is your safety net for catching that fleeting idea that will add strength to a weak part of a research paper (in prep.). I always have a notebook (and at least one pen or pencil) in my inside jacket pocket, plus another in my briefcase (and a pencil case). I don't have one in the shower, and I get at least one worthwhile insight there per year, so I'm thinking of adding writing implements to the medicine cabinet. Napkins are too absorbent for easy writing, and the back of your hand, although difficult to lose, has only limited space for making notes. 


\section{TURN UP FOR WORK (JEANETTE WINTERSON)}

Where do you write? Do you organize specific writing periods every day, or does writing occur at random? If you have a writing hour(s), say, are you good at protecting that time, or does it get eroded by e-mails, phone calls, making cups of coffee, or, to be blunt, sloth and excuses? I wrote the draft of this paragraph on a Post-It note on the train to work. By getting up early, I already had thirty minutes' writing before the family got out of bed (but sleep is important, too, so I don't do this every day). At work I have other projects to deal with, but I have another train journey in the evening and then maybe an hour or so after my son goes to bed. So, in a twenty-four-hour day, I will have devoted two hours to writing this article. I know when my writing times occur, and I use them to write. How painless was that?

\section{PROTECT THE TIME AND SPACE IN WHICH YOU WRITE} (ZADIE SMITH)

Don't write anywhere near a television, radio, CD player, or other weapon of mass distraction. Unplug the telephone-don't panic, most phone calls are not so important that they can't wait an hour or two. Unplug your Internet access, unless you have the iron will not to look at your e-mails and cannot write the next 200 words without reference to certain documents that you know are available online. Close the door. Maybe lock the door. It is difficult to be isolated in the office, but at home you can ensure that the others in your life are asleep, out of the house, or just know that all interruptions are forbidden. As Jonathan Franzen wrote, ${ }^{6}$ " $[\mathrm{i}] \mathrm{t}$ is doubtful that anyone with an internet connection at his workplace is writing [well].” Amen.

\section{READ LOTS (IAN RANKIN)}

To be an expert in any field of study, it is necessary to read both in and around it. Read monographs and textbooks for established ideas, research papers for new ideas, and conference abstracts for breaking ideas. But also read anything you want to outside your field. Even reading for relaxation counts. Whatever you read, you will develop as an academic writer if you use the facility to be informed and influenced by the styles and ideas of other authors, both good and not so good. Add a yellow highlighter to your kit when a book or paper promises to be relevant. 


\section{PROCEED SLOWLY AND TAKE CARE (ANNIE PROULX)}

A reviewer who has few or no corrections to suggest for one of my research papers has not read it slowly enough to notice my spelling errors, flights of fancy, and jumps in logic. Even when I am writing well, I know that I must be cautious. Surplus enthusiasm makes me write too fast and miss steps in an argument. Taking just a little more time to write anything gives me more chance to recognize frailties in my text. A paper that I was too enthusiastic about in 2009 skipped crucial parts of the argument. Rejection was followed by a careful reassessment and rewrite, increasing the paper's length by 30 per cent; resubmission of this improved typescript to a higher-profile journal was successful, and the article is now published. But a slower, more careful approach would have avoided the logical slips of the initial submission.

\section{THE WAY TO WRITE A BOOK IS TO ACTUALLY WRITE A BOOK (ANNIE ENRIGHT)}

This rule is entirely common sense, but how many academics have you met who would like to write more, but are too busy with committee work, have a heavy teaching load or hide behind some other half-truth? I was busy with committee work when I was a head of department and had a heavy teaching load when I worked in a Third World university, but I still kept writing and publishing. If you want to write, then you will write. A variation on this theme is the academic who talks a good writing schedule - 'I am working on monograph X' — without actually putting pen to paper. Similarly, remember the part-time graduate students who will never finish, but who delight in saying 'I am writing my master's thesis' like parrots as long as the university allows them to keep paying their fees.

\section{KEEP A DIARY (GEOFF DYER)}

I don't mean this to be a piece of blotting paper for observations and ideas that will later be recycled. Rather, the academic author must use a diary to get organized. We rarely have the luxury of writing only one book or one paper at a time. This week I have prepared a presentation for a conference, edited a paper for Scripta Geologica, corrected one of my own papers after peer review, sent out a reminder about the approaching deadline for submission for contributors to a thematic 
volume that I am co-editing and, oh yes, written this article for the Journal of Scholarly Publishing. My diary kept me honest and ensured that I remembered to complete all these tasks, enabling me to balance them over a typical working week.

\section{IF YOU GET STUCK, GET AWAY FROM THE DESK (HILARY MANTEL)}

Most often this is a data-processing problem. Your brain needs to be given some air and to step back from the writing problem, which it needs to dodge or dance around until a way in can be determined. My ideal space for dealing with a sticky piece of writing is on a walk through the sand dunes on the Dutch coast. A twelve-kilometre walk away from most other members of the human race has an effect like putting my brain through a brisk wash cycle. Definitely do not forget the notebook-I've sketched out the guts of an entire article on such a head-clearing walk before now.

\section{EDITING IS EVERYTHING (ESTHER FREUd)}

When I worked in a university, the final-year geology majors had a long project to write up. The first draft was almost invariably a shambles, and my red pen would dance across the page as it corrected facts, format, style, spelling, and everything else. In the ensuing interview in my office, I would present the candidate with his or her corrected draft and ask them to open it at any page. Their hearts would sink as they saw my creative ink work. I would then open a drawer of my desk and remove an early draft of one of my papers in preparation, similarly marked in red. My idea was that this would help the students to understand that writing without editing is rare and that every paper can be massaged into better shape.

\section{Finish WhAT YOU'RE WRITING (NEIL GAimAN)}

Rather too obviously, this is my last rule. In the recent past I have put fewer new files into my drawer for stalled research projects and ideas, and I have even taken some out. My utopian ideal is to empty this drawer, and I may yet succeed. But new projects are always more exciting than old ones. The best time to finish any project is as soon as possible. 
STEPHEN K. DONOVAN is a researcher and editor at NCB - Naturalis, Leiden, The Netherlands. He is managing editor of the museum's geological journal, Scripta Geologica, and book-review editor of Geological Journal. His latest monograph is Jamaican Rock Stars 1823-1971: The Geologists Who Explored Jamaica (Geological Society of America 2010).

NOTES

1. With apologies to Elmore Leonard, Elmore Leonard's 1o Rules of Writing (New York: William Morrow 2010)

2. E.g., Sir Alexander Macara, 'How to Deal with Questions,' in George M. Hall, ed., How to Present at Meetings, 2nd ed. (Malden, MA: Blackwell / BMJ Books 2007): 55-61, 57; Richard Hall, Brilliant Presentations: What the Best Presenters Know, Say and Do (Harlow, UK: Pearson Education 2007), 118; Giving Presentations (Boston: Harvard Business School Publishing 2007), 50

3. E.g., Andrew Bradbury, Successful Presentation Skills, 3rd ed. (London: Kogan Page 2006), 74; 'Five Winning Ways to Begin a Presentation,' in Presentations That Persuade and Motivate (Boston: Harvard Business School Press 2004), 71

4. 'Put One Word after Another,' The Guardian, 20 February 2010: 1-5

5. Leonard, Elmore Leonard's 10 Rules of Writing

6. 'Put One Word after Another,' 3 